\title{
Risk Factors Predicting Upper Urinary Tract Damage in Patients With Myelodysplasia: Data Analysis of 637 Cases From A Single Center
}

\author{
Han Deng ${ }^{1,2,3}$, Zhaoxia Wang ${ }^{4}$, Limin Liao ${ }^{1,2,3}$, Juan $\mathrm{Wu}^{1,2}$, Yue Wang ${ }^{1,2}$ \\ ${ }^{1}$ Department of Urology, China Rehabilitation Research Center, Rehabilitation School of Capital Medical University, Beijing, China \\ ${ }^{2}$ Department of Urology, Capital Medical University, Beijing, China \\ ${ }^{3}$ University of Health and Rehabilitation Sciences, Qingdao, China \\ ${ }^{4}$ Department of Rehabilitation Medicine, Beijing Tiantan Hospital, Capital Medical University, Beijing, China
}

Purpose: To determine the risk factors predicting upper urinary tract (UUT) damage using a grading system for upper urinary tract dilation (UUTD) and a descriptive system for all urinary tract dysfunction (AUTD) in patients with myelodysplasia.

Methods: Six hundred thirty-seven patients with myelodysplasia were evaluated at our center from January 2008 to November 2019. Clinical data, ultrasonography, magnetic resonance urography, and video-urodynamics (VUDS) parameters were collected. Univariate and multivariate analyses were used to determine the risk factors predicting UUT damage.

Results: Three hundred eighty-three males and 254 females were included. The average course of lower urinary tract symptoms (LUTS) was $14.08 \pm 7.07$ years (range, 3-31 years). The urodynamic diagnoses of all patients were as follows: detrusor overactivity, 26.8\%; detrusor underactivity, 6.44\%; and acontractile detrusor, $66.72 \%$. UUT damage was determined in $66.56 \%$ of the patients. Of the patients, $28.73 \%$ had vesicoureteral reflux (VUR) during filling (bilateral, $n=50$; unilateral, $n=133$ ) on fluoroscopy during VUDS testing. Two hundred thirty-four patients had UUTD (bilateral, $n=203$; unilateral, $n=31$ ). The occurrence of hydronephrosis based on ultrasonography was closely related to ipsilateral VUR $(\mathrm{P}<0.05)$. Absent of bladder sensation, long-term course of LUTS, decreased maximum cystometric capacity (MCC) and bladder compliance (BC), and increased postvoid residual urine (PVR) were shown to be independent risk factors in logistic regression analysis.

Conclusions: This retrospective study using UUTD and AUTD systems indicated that patients with myelodysplasia have a high incidence of UUT damage. Absence of bladder sensation, long-term course of LUTS, decreased MCC and BC, and increased PVR were independent risk factors predicting UUT damage.

Keywords: Myelodysplasia; Upper urinary tract damage; Video-urodynamics

- Funding Support: This study is supported by the Beijing Natural Science Foundation (7202236).

- Research Ethics: The retrospective review of risk factors predicting upper urinary tract damage in patients with myelodysplasia was approved by the Institutional Review Board of China Rehabilitation Research Centre (No. 2020-127-2).

- Conflict of Interest: No potential conflict of interest relevant to this article was reported.

Corresponding author: Limin Liao (iD https://orcid.org/0000-0002-7092-6576 Department of Urology, China Rehabilitation Research Center, No 10. Jiaomen Beilu, Fengtai District, Beijing 100068, China

Email:Imliao@263.net

Submitted: December 16, 2020 / Accepted after revision: February 8, 2021
This is an Open Access article distributed under the terms of the Creative Commons Attribution Non-Commercial License (http://creativecommons.org/licenses/by-nc/4.0/) which permits unrestricted non-commercial use, distribution, and reproduction in any medium, provided the original work is properly cited. 


\section{INTRODUCTION}

Myelodysplasia is a group of developmental anomalies resulting from defects that occur during neural tube closure [1]. Myelodysplasia is a complicated disease associated with neurologic, musculoskeletal, and genitourinary system abnormalities [2]. Neurologic lesions may include spina bifida occulta, tethered cord syndrome, meningocele, lipomyelomeningocele, or myelomeningocele [1]. Children born with myelodysplasia have lifelong complex health care needs. Myelodysplasia can result in bladder dysfunction with multiple manifestations, including urinary retention and detrusor underactivity (DU), urinary incontinence, detrusor overactivity (DO), sphincter dysfunction, and recurrent urinary infection, which can potentially lead to progressive renal failure requiring dialysis or transplantation [1].

By combining lower urinary tract dysfunction with grading for upper urinary tract (UUT) damage, including vesicoureteral reflux (VUR), upper urinary tract dilation (UUTD), ureterovesical junction stenosis (UVJS), glomerular filtration rate (GFR) of differential kidney and serum creatinine (Scr) level, Liao developed a new description for all urinary tract dysfunction (AUTD), including the upper and lower urinary tracts in patients with neurogenic bladder (NB) [3-6]. AUTD can comprehensively and objectively assess urinary tract function and guide patients to follow-up regularly to avoid missing items [36]. Risk analysis of AUTD can help to differentiate at-risk patients from patients at low risk and develop a neuro-urologic management plan accordingly.

Using the Liao classification for AUTD, we comprehensively evaluated upper and lower urinary tract function of patients with myelodysplasia to determine the risk factors for UUT damage.

\section{MATERIALS AND METHODS}

\section{Patients}

With Institutional Review Board approval (No. 2020-127-2), we retrospectively reviewed the medical records of patients with myelodysplasia who underwent video-urodynamics (VUDS) at our center between January 2008 and July 2020, excluding those who were confirmed or suspected to be polyuria through detailed history inquiry. The clinical data, ultrasonography, magnetic resonance urography (MRU) and VUDS findings were reviewed. The VUDS consisted of cystometry and simul- taneous cystography according to the "Good Urodynamic Practices" recommended by the International Continence Society (ICS) [7]. Iopromide $(15 \%-20 \%)$ at $36^{\circ} \mathrm{C}$ was infused at a rate of $10-20 \mathrm{~mL} / \mathrm{min}$. Neither anesthesia or sedation was used. The filling was discontinued when urine leakage occurred, the detrusor pressure exceeded $40 \mathrm{~cm} \mathrm{H}_{2} \mathrm{O}$, VUR occurred, and a strong desire to urinate or an uncomfortable feeling was present. The patients had negative surgical histories, with the exception of spinal or myelomeningocele closure surgery.

\section{Assessment}

$\mathrm{DO}$ is characterized by the occurrence of involuntary detrusor contractions during filling cystometry; DO may be spontaneous or provoked [8]. The ICS defines DU as a contraction of reduced strength and/or duration, resulting in prolonged bladder emptying and/or a failure to achieve complete bladder emptying within a normal time span [9]. An acontractile detrusor (AcD) cannot contract during urodynamic studies, thus resulting in prolonged bladder emptying within a normal time span [8]. The resting urethral pressure profile precedes cystometry. According to the ICS, bladder sensation is divided into normal, increased, reduced, and absent [10]. The maximum cystometric capacity (MCC) is the bladder volume at the end of the filling cystometrogram. Maximum detrusor pressure (MDP) is defined as the maximal value of detrusor pressure recorded during filling. Bladder compliance (BC) was calculated by dividing the volume change by the change in detrusor pressure during the change in bladder volume [11]. The postvoid residual urine (PVR) was recorded after in-and-out catheterization.

VUR was identified by VUDS and graded by the International Reflux Grading System [12]. An intravesical VUR pressure $<10 \mathrm{~cm} \mathrm{H}_{2} \mathrm{O}$ was considered to be low-pressure VUR [13]. Hydronephrosis and ureter dilation were graded according to the Liao UUTD grading system [3-6]. UVJS was determined by MRU. The Scr level was used to evaluate global kidney function. The GFR from the diuretic renography was used to evaluate the differential renal function of each kidney. The UUT was considered to represent damage if any of the following were described unilaterally or bilaterally: (1) any grade VUR; (2) $\geq 1$ grade UUTD or UVJS: grade 1: There is slight separation of the central renal complex, but no visualized calices; the ureter is $<7$ $\mathrm{mm}$ from the coronal and transverse MRU images and the maximum intensity projection MRU; grade 2 : The renal pelvis is dilated, one or more calices may be visualized, but the renal parenchyma over the calices is normal; the ureter is $<10 \mathrm{~mm}$ 
from the coronal and transverse MRU images and the maximum intensity projection MRU; grade 3: The renal pelvis is further dilated and there are fluid-filled calices throughout the kidney. The renal parenchyma over the calices is beginning to thin, but the renal parenchyma loss is $<50 \%$. The ureter is tortuous and $<15 \mathrm{~mm}$ from the coronal and transverse MRU images and the maximum intensity projection MRU; grade 4: As in grade 3, but the renal parenchyma is significantly thinned (renal parenchyma loss $>50 \%$ ). The ureter is severely tortuous and $>15 \mathrm{~mm}$ from the coronal and transverse MRU images and the maximum intensity projection MRU; (3) $\geq 1$ grade hydronephrosis according to the Society for Fetal Urology ultrasound grading system [14]; and (4) elevated Scr (>1.5 mg/dL).

\section{Statistical Analysis}

Data are expressed as the mean \pm standard deviation. IBM SPSS Statistics ver. 25.0 (IBM Co., Armonk, NY, USA) was used for statistical analysis. Frequency (percentage) was used to describe the count data. Chi-square and Fisher exact tests were used for comparison between groups. The measurement data were first tested for normality. The data that did not follow a normal distribution were described by the median (interquartile range). The Mann-Whitney U-test was used for comparisons between groups. Binary logistic regression was used to determine the factors predictive of UUT damage. A P-value of $<0.05$ was considered statistically significant.

\section{RESULTS}

Patient characteristics and VUDS findings are summarized in Table 1. Six hundred thirty-seven patients (383 males and 254 females) were included. The average age was $21.51 \pm 11.25$ years (range, 4-66 years). The average course of lower urinary tract symptoms (LUTS) was 14.08 \pm 7.07 years (range, 3-31 years). The proportion of patients who had taken LUTS drugs was $35.01 \%(n=223)$. The percentage of patients who had and had not undergone spinal or myelomeningocele closure surgery was $80.85 \%(n=515)$ and $19.15 \%(n=122)$, respectively. The bladder management methods for patients who have been continuous for $>6$ months were voluntary micturition $(2.04 \%, 13$ of 637), abdominal pressure-assisted urination (83.83\%, 534 of 637), intermittent catheterization [IC] (6.75\%, 43 of 637), and indwelling urethral catheterization [IDUC] (7.38\%, 47 of 637). Among the 637 patients, 171 (26.8\%), 41 (6.44\%), and 425 (66.72\%) were diagnosed with DO, DU, and AcD, respectively,
Table 1. Patient characteristics and VUDS findings

\begin{tabular}{|c|c|}
\hline Variable & Value \\
\hline \multicolumn{2}{|l|}{ Sex } \\
\hline Male & $383(60.13)$ \\
\hline Female & $254(39.87)$ \\
\hline Age (yr) & $21.51 \pm 11.25$ \\
\hline Course of LUTS (yr) & $14.08 \pm 7.07$ \\
\hline History of drug usage for LUTS & $223(35.01)$ \\
\hline \multicolumn{2}{|l|}{ Spinal or myelomeningocele closure surgeries } \\
\hline Yes & $515(80.85)$ \\
\hline No & $122(19.15)$ \\
\hline \multicolumn{2}{|l|}{ Bladder management method } \\
\hline Voluntary micturition & $13(2.04)$ \\
\hline Abdominal pressure-assisted urination & $534(83.83)$ \\
\hline IC & $43(6.75)$ \\
\hline IDUC & $47(7.38)$ \\
\hline \multicolumn{2}{|l|}{ Urodynamic diagnosis } \\
\hline DO & $171(26.84)$ \\
\hline DU & $41(6.44)$ \\
\hline $\mathrm{AcD}$ & $425(66.72)$ \\
\hline \multicolumn{2}{|l|}{ Bladder sensation } \\
\hline Normal & $206(32.34)$ \\
\hline Increased & $215(33.75)$ \\
\hline Reduced & $64(10.05)$ \\
\hline Absent & $152(23.86)$ \\
\hline $\operatorname{MCC}(\mathrm{mL})$ & $205.90 \pm 147.79$ \\
\hline $\mathrm{MDP}\left(\mathrm{cm} \mathrm{H}_{2} \mathrm{O}\right)$ & $36.35 \pm 27.53$ \\
\hline $\mathrm{BC}\left(\mathrm{mL} / \mathrm{cm} \mathrm{H}_{2} \mathrm{O}\right)$ & $12.79 \pm 16.90$ \\
\hline \multicolumn{2}{|l|}{ DSD } \\
\hline Yes & $105(16.48)$ \\
\hline No & $532(83.52)$ \\
\hline $\operatorname{PVR}(\mathrm{mL})$ & $186.00 \pm 152.06$ \\
\hline $\operatorname{MUCP}\left(\mathrm{cm} \mathrm{H}_{2} \mathrm{O}\right)$ & $77.50 \pm 31.44$ \\
\hline
\end{tabular}

Values are presented as number (\%) or mean \pm standard deviation. VUDS, video-urodynamics; LUTS, lower urinary tract symptoms; IC, intermittent catheterization; IDUC, indwelling urethral catheter; DO, detrusor overactivity; DU, detrusor underactivity; $\mathrm{AcD}$, acontractile detrusor; MCC, maximum cystometric capacity; MDP, maximum detrusor pressure; BC, bladder compliance; DSD, detrusor-sphincter dyssynergia; PVR, postvoid residual urine; MUCP, maximum urethral closure pressure.

\section{based on VUDS testing.}

Of the patients, 28.73\% ( $\mathrm{n}=183)$ had VUR during cystometry on fluoroscopy during VUDS testing. The left, right, and bilateral VUR ratios were $47.54 \%(n=87), 25.14 \%(n=46)$, and 
Table 2. Relationship between hydronephrosis measured by ultrasound and ipsilateral VUR

\begin{tabular}{lrcrc}
\hline Hydronephrosis & VUR & Non-VUR & Total & P-value \\
\hline Yes & 175 & 436 & 611 & \\
No & 58 & 604 & 662 & $<0.05$ \\
Total & 233 & 1,014 & 1,273 & \\
\hline
\end{tabular}

Values are presented as number of ureters.

VUR, vesicoureteral reflux.

$27.32 \%(n=50)$, respectively. The distribution of VUR from I-V degrees was 24, 40, 51, 41, and 77, respectively, in 233 ureters. The ratios of low- and high-pressure VUR were $60.94 \%(n=142)$ and $39.06 \%(\mathrm{n}=91)$, respectively. Among 248 patients who underwent MRU, 234 had UUTD (bilateral, $n=203$; unilateral, $\mathrm{n}=31$ ). The distribution of UUTD from 1-4 degrees, according to the mentioned [3-6] grading system was 85, 95, 104, and 153, respectively, in 437 ureters.

Ninety-three patients (37.5\%) had UVJS with 131 ureters (bilateral, $\mathrm{n}=38$; left, $\mathrm{n}=25$; and right, $\mathrm{n}=30$ ). A Scr $>1.5 \mathrm{mg} / \mathrm{dL}$ was demonstrated in 68 of 295 patients, with a mean level of 107.2 $\pm 81.6 \mu \mathrm{moI} / \mathrm{L}$ (range, $24-653 \mu \mathrm{moI} / \mathrm{L}$ ). Three hundred thirty-five kidneys from 248 patients had a GFR $<50 \mathrm{~mL} / \mathrm{min}$ (left, $\mathrm{n}=164$; right, $\mathrm{n}=171$ ). As shown in Table 2, hydronephrosis based on ultrasonography was closely related to ipsilateral VUR (a case of monokidney). Low- or high-pressure VUR had no statistical association with VUR grade (Table 3).

Four hundred twenty-four patients (66.56\%) had UUT damage (Table 4). Based on univariate analysis, course of LUTS, bladder sensation, MCC, MDP, BC, PVR, and the bladder management method were shown to be statistically significant factors affecting UUT damage in patients with myelodysplasia (Table 4). Furthermore, we found that the absence of bladder sensation, long-term course of LUTS, decreased MCC and BC, and increased PVR were independent risk factors predicting UUT damage based on logistic regression analysis (Table 5).

\section{DISSCUSION}

In this study we retrospectively analyzed the characteristics of upper and lower urinary tract functions in patients with myelodysplasia. The results were as follows: (1) Hydronephrosis is closely related to ipsilateral VUR. (2) Absence of bladder sensation, long-term course of LUTS, decreased MCC and BC, and increased PVR are risk factors predicting UUT damage.

Urodynamic diagnoses in patients with myelodysplasia are
Table 3. Relationship between the detrusor pressure and the grade of VUR

\begin{tabular}{lccrl}
\hline Parameter & $\begin{array}{c}\text { Low-grade } \\
\text { VUR }\end{array}$ & $\begin{array}{c}\text { High-grade } \\
\text { VUR }\end{array}$ & Total & P-value \\
\hline Low-pressure VUR & 29 & 113 & 142 & \\
High-pressure VUR & 22 & 69 & 91 & $>0.05$ \\
Total & 51 & 182 & 233 &
\end{tabular}

Values are presented as number of ureters.

VUR, vesicoureteral reflux.

diverse. In this study $66.72 \%$ of patients had AcD, $26.84 \%$ of patients had DO, and $6.44 \%$ of patients had DU. The multiplicity of VUDS diagnoses demonstrated that spinal cord injury is multifocal and the nerve damage may be primarily in the cone. This study also found that long-term LUTS course is an independent risk factor for UUT damage. The above data suggests that all patients with myelodysplasia have lower urinary tract dysfunction, and with the extension of the course of disease, the UUT damage is more serious; however, it needs to be further explained that in China, patients with myelodysplasia undergo neurosurgery early and go to a urology department late, and the lack of attention, correct management of the bladder, longterm regular drug usage and follow-up after surgery lead to UUT damage. So, we recommend that patients with myelodysplasia undergo regular Scr, VUDS and urinary tract ultrasound examinations, and adopt different bladder management plans based on the examination results. If no UUT damage is found, BC is good, bladder capacity is normal, but there are more PVR, IC is recommended; If UUT damage is found, further MRU and nephrogram examinations are required. According to the severity, it is recommended to perform drug therapy combined with IC, or augmentation cystoplasty combined with IC; If severe $\mathrm{DO}$ is found and $\mathrm{BC}$ is extremely poor, augmentation cystoplasty combined with IC is recommended. All patients are recommended to review regularly the above items every year in order to adjust the treatment and follow-up plan in time to better protect the UUT.

The rate of UUT damage is high and the degree of damage is more severe than traumatic spinal cord injury. Bennett et al. [15] pointed out that IDUC may aggravate urinary tract complications and increase the incidence of UUT damage. Chao et al. [16] did not find a significant difference in creatinine clearance between IDUC and spontaneous voiding. Weld et al. [17] showed that although all bladder management methods help to protect renal function, chronic IDUC may lead to renal deterio- 
Table 4. Univariate analysis for UUT damage

\begin{tabular}{|c|c|c|c|c|}
\hline \multirow{2}{*}{ Variable } & \multicolumn{2}{|c|}{ UUT damage } & \multirow{2}{*}{$\mathrm{Z} / \mathrm{c} 2$} & \multirow{2}{*}{ P-value } \\
\hline & No & Yes & & \\
\hline Sex & & & 0.277 & 0.599 \\
\hline Male & $125(32.64)$ & $258(67.36)$ & & \\
\hline Female & $88(34.65)$ & $166(65.35)$ & & \\
\hline Age (yr) & $20(12-32)$ & $20(14-27)$ & -0.773 & 0.439 \\
\hline Course of LUTS (yr) & $11(7-19)$ & $15(8-20)$ & -3.197 & 0.001 \\
\hline History of drug usage for LUTS & & & 0.064 & 0.801 \\
\hline Yes & 76 & 147 & & \\
\hline No & 137 & 277 & & \\
\hline Spinal or myelomeningocele closure surgeries & & & 2.365 & 0.124 \\
\hline Yes & $48(39.34)$ & $74(60.66)$ & & \\
\hline No & $165(32.04)$ & $350(67.96)$ & & \\
\hline Urodynamic diagnosis & & & 4.541 & 0.103 \\
\hline DO & $65(38.01)$ & $106(61.99)$ & & \\
\hline DU & $23(54.76)$ & $18(43.90)$ & & \\
\hline $\mathrm{AcD}$ & $172(40.47)$ & $253(59.53)$ & & \\
\hline Bladder sensation & & & 33.226 & $<0.001$ \\
\hline Normal & $84(40.78)$ & $122(59.22)$ & & \\
\hline Increased & $68(31.63)$ & $147(68.37)$ & & \\
\hline Reduced & $34(53.13)$ & $30(46.88)$ & & \\
\hline Absent & $27(17.76)$ & $125(82.24)$ & & \\
\hline $\operatorname{MUCP}\left(\mathrm{cm} \mathrm{H}_{2} \mathrm{O}\right)$ & $70(52.5-98.5)$ & $72.5(59-96)$ & -1.426 & 0.154 \\
\hline $\operatorname{MCC}(\mathrm{mL})$ & $268(166-400)$ & $128(60-255.5)$ & -9.002 & $<0.001$ \\
\hline $\mathrm{MDP}\left(\mathrm{cm} \mathrm{H}_{2} \mathrm{O}\right)$ & $27(12-50)$ & $33(18-50)$ & -2.218 & 0.027 \\
\hline $\mathrm{BC}\left(\mathrm{mL} / \mathrm{cm} \mathrm{H}_{2} \mathrm{O}\right)$ & $13(7-23)$ & $6(3-9)$ & -10.057 & $<0.001$ \\
\hline DSD & & & 1.913 & 0.167 \\
\hline Yes & $29(27.62)$ & $76(72.38)$ & & \\
\hline No & $184(34.59)$ & $348(65.41)$ & & \\
\hline PVR & $207(72.5-400)$ & $128(56-250)$ & -4.163 & $<0.001$ \\
\hline Bladder management method & & & - & 0.048 \\
\hline Voluntary micturition & $7(53.85)$ & $6(46.15)$ & & \\
\hline Abdominal pressure-assisted urination & $177(33.15)$ & $357(66.85)$ & & \\
\hline IC & $19(44.19)$ & $24(55.81)$ & & \\
\hline IDUC & $10(21.28)$ & $37(78.72)$ & & \\
\hline
\end{tabular}

Values are presented as number (\%) or median (interquartile range).

UUT, upper urinary tract; LUTS, lower urinary tract symptoms; DO, detrusor overactivity; DU, detrusor underactivity; AcD, acontractile detrusor; MUCP, maximum urethral closure pressure; MCC, maximum cystometric capacity; MDP, maximum detrusor pressure; BC, bladder compliance; DSD, detrusor-sphincter dyssynergia; PVR, postvoid residual urine; IC, intermittent catheterization; IDUC, indwelling urethral catheter.

ration. Dik et al. [18] found that IC for early childhood spina bifida to ensure low pressure in the bladder can protect the UUT to a certain extent. However, in this study, we did not find that a certain type of bladder management is an independent risk factor for UUT damage, which may be caused by the uneven distribution of bladder management data in this study because IC is not popular in China.

Bladder sensation is an important part of urinary function, 
Table 5. Multivariate analyses of UUT damage

\begin{tabular}{llll}
\hline Variable & OR & 95\% CI & P-value \\
\hline Bladder sensation & & & 0.007 \\
Normal & 1.000 & & 0.435 \\
Increased & 0.831 & $0.497-1.248$ & 0.697 \\
Reduced & 1.142 & $0.585-2.125$ & 0.005 \\
Absent & 2.267 & $1.190-3.690$ & $<0.001$ \\
Course of LUTS & 1.050 & $1.022-1.079$ & $<0.001$ \\
MCC & 0.992 & $0.989-0.995$ & 0.217 \\
MDP & 0.996 & $0.988-1.003$ & 0.001 \\
BC & 0.977 & $0.963-0.991$ & 0.003 \\
PVR & 1.004 & $1.001-1.006$ & 0.114 \\
Bladder management method & & & 0.485 \\
Voluntary micturition & 1.000 & $0.158-2.401$ & 0.168 \\
Abdominal pressure-assisted urination & 0.616 & $0.077-1.561$ & 0.116 \\
IC & 0.347 & 0.270 & \\
IDUC & & & \\
\hline
\end{tabular}

UUT, upper urinary tract; OR, odds ratio; CI, confidence interval; LUTS, lower urinary tract symptoms; MCC, maximum cystometric capacity; MDP, maximum detrusor pressure; BC, bladder compliance; PVR, postvoid residual urine; IC, intermittent catheterization; IDUC, indwelling urethral catheter.

and can guide the daily urination behavior of healthy individuals. Indeed, individuals with normal bladder sensation can determine when to urinate and can prevent the destructive effects of overdilation of the bladder. Evaluation of bladder sensation during urodynamic studies, which guides daily urinary behavior, is important. Our results showed that the absence of bladder sensation is an independent risk factor for UUT damage. Patients with sensory loss have more urine storage in the bladder, increased bladder capacity and residual urine, and high pressure in the bladder, which may cause VUR and damage the UUT.

UUT damage adversely affects the long-term lives of patients with myelodysplasia. The detrusor contractile function in patients with myelodysplasia is a progressive, pathologic process. In this study the number of patients with $\mathrm{DO}, \mathrm{DU}$, and $\mathrm{AcD}$ was $26.84 \%, 6.44 \%$, and $66.72 \%$, respectively. Impaired detrusor contractility is accompanied by increased PVR and MDP, and decreased MCC and BC, resulting in UUT damage. A longterm increase in PVR may cause inflammation of the lower urinary tract and even cause repeated infections. Inflammation and infection of the lower urinary tract can accelerate fibrosis of the bladder wall. Ozkan et al. [19] showed that histologically, severe detrusor fibrosis may be a risk factor for UUT damage.
Orellana et al. [20] reported that moderate and severe fibrosis of the detrusor muscle is a risk factor for UUT damage during a full-thickness pathologic biopsy of the bladder wall intra-operatively. Fibrosis of the bladder wall can lead to a decrease in MCC and BC, and an increase in MDP, which can further aggravate fibrosis and increase the workload of the ureter to transport urine to the bladder and damage the vesicoureteral antireflux mechanism. Over time, ureteral function is decompensated, resulting in VUR, ureteral dilation, and hydronephrosis. It has been suggested that a MCC $<200 \mathrm{~mL}$ is significantly associated with UUT damage [21]. The low BC is associated with UUT damage and is one of the major risk factors [22]. In our study logistic regression analysis indicated that the decrease in bladder volume and $\mathrm{BC}$, and the increase in PVR were independent risk factors for UUT damage. Simforoosh et al. [23] only performed bladder enlargement to improve BC and bladder capacity in patients with a low-compliant bladder after conservative treatment failure, but did not assess VUR. After follow-up, VUR resolved completely in $85.4 \%$ of patients.

Protecting UUT function is an extremely important goal in NB patient management. The morphology and innervation of the ureterovesical junction play an important role in the occurrence of VUR, especially in NB patients with a long disease his- 
tory [24]. A lengthy course of NB and suboptimal bladder management may be the causes of VUR, UUTD, or UUT damage. Reduced BC secondary to progressive fibrosis of the bladder wall is an important factor in the occurrence of VUR. In this study most patients had severe VUR and UUTD. The gradual destruction of the bladder wall causes reduced $\mathrm{BC}$, detrusor fibrosis, and thickening of the detrusor muscle, which often lead to ureteral stenosis in the bladder wall or UVJS, an important factor in the occurrence of UUTD [3-6]. UVJS usually leads to hydronephrosis, ureteric dilatation, tortuosity, adhesions, and renal failure. The sites of obstruction usually begin at the UVJS, and fibrotic cords always form at tortuous points. UUTD and VUR often cause chronic renal failure in NB patients. A patient with UUTD, tortuous knotting ureter and UVJS should undergo ureteral tailoring/shortening and reimplantation during augmentation cystoplasty and renal function could be fully protected. Therefore, evaluation using UUTD and AUTD systems can provide us with objective indicators for the conditions of upper and lower urinary tract function and is also an important part of early guidance and treatment.

There was a significant difference between the presence or absence of VUR and the appearance of hydronephrosis, and the incidence of hydronephrosis was higher in patients with VUR. DeLair et al. [25] conducted a study involving patients with myelodysplasia and found that VUR is an independent risk factor for renal cortex damage. These results suggest that if the patient can manage the bladder in a timely and reasonable manner to prevent or reduce VUR, kidney function may be protected.

In the present study there was no statistical difference in the degree of VUR between low- and high-pressure VUR. We speculate that the antireflux mechanism of the bladder and ureters in patients with myelodysplasia may be damaged, but it is unclear why the left VUR (47.54\%) is greater than the right (25.14\%) and bilaterally (27.32\%); further research is needed to better understand this finding.

The main limitations of this retrospective study were as follows: (1) because some patients were outpatients, UUTD status, GFR, and Scr were not available; (2) most patients had only one VUDS examination in our center, so we did not observe the dynamic changes of urinary tract function.

In conclusion, the current study showed that the UUTD and AUTD systems comprehensively and effectively evaluated the upper and lower urinary tract function of patients with myelodysplasia, and can be used for longitudinal monitoring of uri- nary tract function of patients without missing items. The current retrospective study using these systems indicates that patients with myelodysplasia have a high incidence of UUT damage. The absence of bladder sensation, long-term course of LUTS, decreased MCC and BC, and increased PVR were independent risk factors predicting UUT damage in patients with myelodysplasia.

\section{AUTHOR CONTRIBUTION STATEMENT}

- Conceptualization: $L L$

- Data curation: $L L, J W$

- Formal analysis: $H D, Z W$

- Methodology: HD, YW

- Project administration: $L L$

- Visualization: $H D$

-Writing-original draft: $H D$

-Writing-review \& editing: $H D$

\section{ORCID}

$\begin{array}{ll}\text { Han Deng } & 0000-0002-9509-8623 \\ \text { Zhaoxia Wang } & 0000-0003-2767-4956 \\ \text { Limin Liao } & 0000-0002-7092-6576 \\ \text { Juan Wu } & 0000-0002-1754-8465 \\ \text { Yue Wang } & 0000-0002-9105-0219\end{array}$

\section{REFERENCES}

1. Favazza TF. Myelodysplasia and neurogenic bladder dysfunction [Internet]. New York: Medscape, LLC; 2020 [cited 2016 Aug 30; updated 2020 Apr 3]. Available from: https://emedicine.medscape. com/article/1015695-overview.

2. Tarcan T, Sekerci CA, Akbal C, Tinay I, Tanidir Y, Sahan A, et al. Is $40 \mathrm{~cm} \mathrm{H}_{2} \mathrm{O}$ detrusor leak point pressure cut-off reliable for upper urinary tract protection in children with myelodysplasia? Neurourol Urodyn 2017;36:759-63.

3. Liao L, Zhang F, Chen G. New grading system for upper urinary tract dilation using magnetic resonance urography in patients with neurogenic bladder. BMC Urology 2014;14:38.

4. Liao L, Zhang F, Chen G. Midterm outcomes of protection for upper urinary tract function by augmentation enterocystoplasty in patients with neurogenic bladder. Int Urol Nephrol 2014;46:211725.

5. Liao L. A new comprehensive classification system for both lower 
and upper urinary tract dysfunction in patients with neurogenic bladder. Urol Int 2015;94:244-8.

6. Liao L. Upper urinary tract dilation. In: Liao L, Madersbacher H, editors. Neurourology. Dordrecht (The Netherlands): Springer; 2019. p. 425-31.

7. Schäfer W, Abrams P, Liao L, Mattiasson A, Pesce F, Spangberg A, et al. Good urodynamic practices: uroflowmetry, filling cystometry, and pressure-flow studies. Neurourol Urodyn 2002;21:261-74.

8. Haylen BT, de Ridder D, Freeman RM, Swift SE, Berghmans B, Lee J, et al. An International Urogynecological Association (IUGA)/International Continence Society (ICS) joint report on the terminology for female pelvic floor dysfunction. Neurourol Urodyn 2010; 29:4-20.

9. Abrams P, Cardozo L, Fall M, Griffiths D, Rosier P, Ulmsten U, et al. The standardisation of terminology of lower urinary tract function: report from the Standardisation Sub-committee of the International Continence Society. Am J Obstet Gynecol 2002;187:11626.

10. Abrams P, Cardozo L, Fall M, Griffiths D, Rosier P, Ulmsten U, et al. The standardization of terminology of lower urinary tract function: report from the standardization sub-committee of the International Continence Society. Neurourol Urodyn 2002;21:167-78.

11. Stöhrer M, Goepel M, Kondo A, Kramer G, Madersbacher H, Millard R, et al. The standardization of terminology in neurogenic lower urinary tract dysfunction: with suggestions for diagnostic procedures. International Continence Society Standardization Committee. Neurourol Urodyn 1999;18:139-58.

12. Duckett JW, Bellinger MF. A plea for standardized grading of vesicoureteral reflux. Eur Urol 1982;8:74-7.

13. Wang Z, Liao L. Effectiveness and complications of augmentation cystoplasty with or without nonrefluxing ureteral reimplantation in patients with bladder dysfunction: a single center 11-year experience. J Urol 2018;199:200-5.

14. Fernbach SK, Maizels M, Conway JJ. Ultrasound grading of hydronephrosis: introduction to the system used by the Society for Fetal Urology. Pediatr Radiol 1993;23:478-80.

15. Bennett CJ, Young MN, Adkins RH, Diaz F. Comparison of blad- der management complication outcomes in female spinal cord injury patients. J Urol 1995;153:1458-60.

16. Chao R, Clowers D, Mayo ME. Fate of upper urinary tracts in patients with indwelling catheters after spinal cord injury. Urology 1993;42:259-62.

17. Weld KJ, Wall BM, Mangold TA, Steere EL, Dmochowski RR. Influences on renal function in chronic spinal cord injured patients. J Urol 2000;164:1490-3.

18. Dik P, Klijn AJ, van Gool JD, de Jong-de Vos van Steenwijk CC, de Jong TP. Early start to therapy preserves kidney function in spina bifida patients. Eur Urol 2006;49:908-13.

19. Ozkan B, Demirkesen O, Durak H, Uygun N, Ismailoglu V, Cetinel B. Which factors predict upper urinary tract deterioration in overactive neurogenic bladder dysfunction? Urology 2005;66:99-104.

20. Orellana P, Baquedano P, Rangarajan V, Zhao JH, Eng ND, Fettich J, et al. Relationship between acute pyelonephritis, renal scarring, and vesicoureteral reflux. Results of a coordinated research project. Pediatr Nephrol 2004;19:1122-6.

21. Zhang Z, Liao L. Risk factors predicting upper urinary tract deterioration in patients with spinal cord injury: a prospective study. Spinal Cord 2014;52:468-71.

22. Gerridzen RG, Thijssen AM, Dehoux E. Risk factors for upper tract deterioration in chronic spinal cord injury patients. J Urol 1992;147: 416-8.

23. Simforoosh N, Tabibi A, Basiri A, Noorbala MH, Danesh AD, Ijadi A. Is ureteral reimplantation necessary during augmentation cystoplasty in patients with neurogenic bladder and vesicoureteral reflux? J Urol 2002;168(4 Pt 1):1439-41.

24. Juhasz Z, Somogyi R, Vajda P, Oberritter Z, Fathi K, Pinter AB. Does the type of bladder augmentation influence the resolution of pre-existing vesicoureteral reflux? Urodynamic studies. Neurourol Urodyn 2008;27:412-6.

25. DeLair SM, Eandi J, White MJ, Nguyen T, Stone AR, Kurzrock EA. Renal cortical deterioration in children with spinal dysraphism: analysis of risk factors. J Spinal Cord Med 2007;30 Suppl 1(Suppl 1):S30-4. 